\title{
X-Ray Emission from National Ignition Facility Indirect Drive Targets
}
A. T. Anderson, R. A. Managan,
M. T. Tobin, and P. F. Peterson
RECENTED
AUG 164996
○STI

This paper was prepared for submittal to the American Nuclear Society 12th Topical Meeting on the

Technology of Fusion Energy Reno, NV

June 16-20, 1996

June 4, 1996
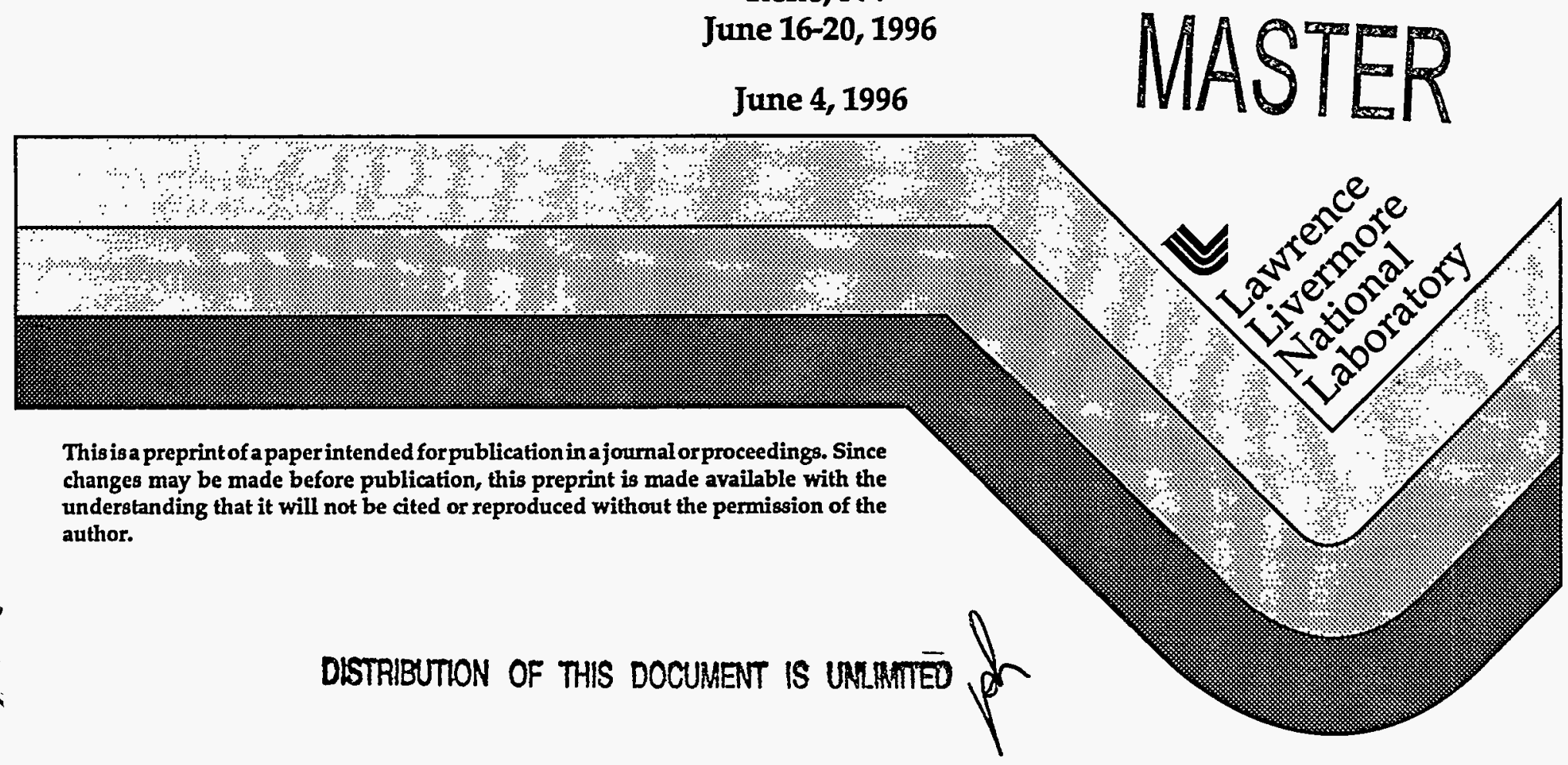


\section{DISCLAIMER}

This document was prepared as an account of work sponsored by an agency of the United States Government. Neither the United States Government nor the University of California nor any of their employees, makes any warranty, express or implied, or assumes any legal liability or responsibility for the accuracy, completeness, or usefulness of any information, apparatus, product, or process disclosed, or represents that its use would not infringe privately owned rights. Reference herein to any specific commercial product, process, or service by trade name, trademark, manufacturer, or otherwise, does not necessarily constitute or imply its-endorsement, recommendation, or favoring by the United States Government or the University of California. The views and opinions of authors expressed herein do not necessarily state or reflect those of the United States Government or the University of California, and shall not be used for advertising or product endorsement purposes. 


\section{DISCLAIMER}

Portions of this document may be illegible in electronic image products. Images are produced from the best available original document. 


\section{X-Ray Emission from National Ignition Facility Indirect Drive Targets}

Andrew T. Anderson

LINL

P.O. Box 808

Livermore, CA 94551

(510) 423-9634
Robert A. Managan

LLNL

P.O. Box 808

Livermore, CA 94551

(510) 423-0903
Michael T. Tobin

LINL

P.O. Box 808

Livermore, CA 94551

(510) 423-1168
Per F. Peterson

U. C. Berkeley

4111 Etchevery Hall

Berkeley, CA 94720

(510) 643-7749

\section{ABSTRACT}

We have performed a series of 1-D numerical simulations of the $x$-ray emission from National Ignition Facility (NIF) targets. Results are presented in terms of total $x$-ray energy, pulse length, and spectrum. Scaling of $x$-ray emissions is presented for variations in both target yield and hohlraum wall thickness. Experiments conducted on the Nova facility provide some validation of the computational tools and methods.

\section{- I. INTRODUCTION}

Target chamber designs for ICF (Inertial Confinement Fusion) facilities must ensure that all performance requirements are met. For the NIF, survival of the final optics is the primary goal. The threat to final optics from direct (target $\mathrm{X}$-rays and debris) and indirect (debris from ablation of chamber components) sources must be evaluated. Accurate knowledge of the x-ray emissions from NIF targets is a critical first step in this process.

Calculation of $x$-ray emission from an ICF target requires complex treatment of many physics processes. LASNEX $^{1}$, a 2-D radiation-hydrodynamics code with an extensive history of ICF development and experimental validation, is believed to be the best code to make these detailed predictions. A number of 1-D LASNEX calculations have been run out to late times to characterize target output variations with both target yield and hohlraum wall thickness. Some preliminary 2-D results are also available 2 . This paper describes the calculations and details NIF $\mathrm{x}$-ray source term predictions.

\section{MODEL DESCRIPTION}

The baseline NIF target design is based on the indirect drive concept ${ }^{3}$. The DT fuel capsule is surrounded by a cylindrical gold hohlraum. Laser beams enter the hohlraum through holes in the end faces and strike the inner surface of the gold walls. The laser pulse is $20 \mathrm{~ns}$ long, with $80 \%$ of the energy coming in the last 3-4 ns. The laser energy is efficiently converted to $x$ rays, which provide uniform illumination of the capsule. The $x$ rays drive the compression of the solid DT fuel shell by ablating the outer $\mathrm{CH}$ layer of the capsule. Figure 1 shows the baseline target and the 1-D model approximation.
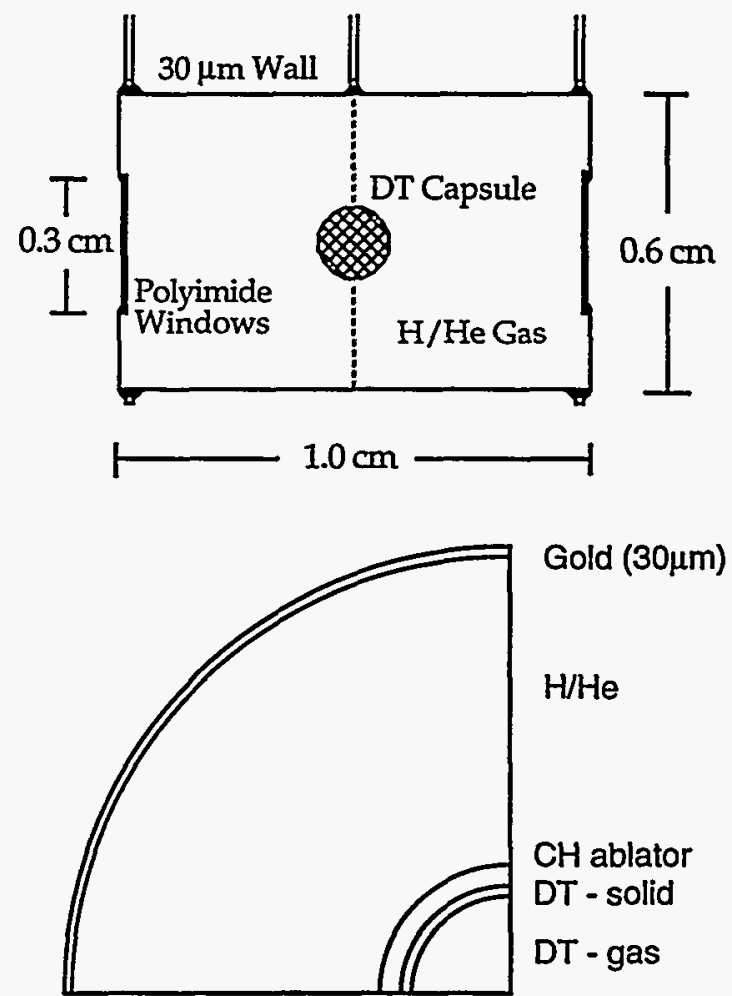

Figure 1: Baseline NIF Target Design and 1-D Model Approximation

The LASNEX model used for this study is a 1-D spherical approximation to the NIF target design. The spherical capsule is modeled well in this case, except that no nonuniformities, instabilities, or mixing of layers are possible. In this respect, the 1-D model will produce the upper limit for yield in any given target design (30 MJ in this case). A more realistic limit is about $20 \mathrm{MJ}$ yield. The surface area of the hohlraum wall in the model matches that of the NIF target by appropriate choice of the inner radius of the gold shell.

To approximate the effect of the laser entrance holes $(\mathrm{LEH})$, radiation is permitted to leave the interior of the 
gold sphere directly by using a "leak source". The model applies this leak source (actually an energy sink in this case) to the $\mathrm{H} / \mathrm{He}$ region between the capsule and the gold interior. Gold vapor expanding from the interior walls may partially or completely close the LEH openings. Resolution of this issue will require 2-D calculations and some experimentation. Until these data are available, two limiting scenarios will serve to bound the problem. One models a quickly closing LEH, while the other leaves the entrance holes open for the duration of the simulation. Figure 2 shows these models.

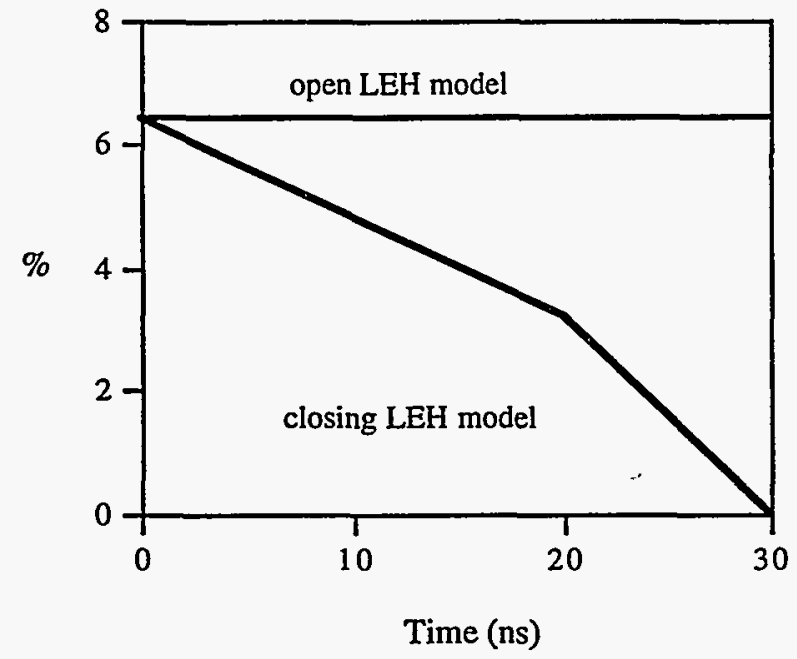

Figure 2: Fraction of 1-D surface area free to radiate directly from hohlraum interior. Laser pulse runs from $t=0$ to 20 ns.

One parameter of the target design that can be modified without significantly affecting the capsule yield is the thickness of the gold hohlraum wall, provided that some minimum value is maintained. With a wall that is thicker than nominal, it is expected that $\mathrm{x}$-ray output would be reduced at the expense of increased debris generation. A thinner wall would conversely move the $x-$ ray/debris split in the opposite direction. LASNEX runs were performed at different hohlraum wall thicknesses, using the same inside radius as the baseline model. All runs used a nominally 30-MJ-yield capsule design.

This study also determined target output with a range of capsule yields. The parameter used to give different yields was the DT gas density inside the fuel shell. Work must be done against the internal gas by the converging fuel, so the peak density falls for higher gas densities, which reduces yield. Different gas densities gave a range of yields from the nominal $30 \mathrm{MJ}$ down to $0.5 \mathrm{MJ}$.

The simulations were taken out to very long times (for LASNEX runs) of at least $150 \mathrm{~ns}$. The criterion for a minimum stop time was that the internal energy remaining in the hot gold had to drop to a small part $(<5 \%)$ of the total non-neutron energy. After this time, $x-$ ray emission is negligible and the remaining energy is in debris kinetic energy.

\section{PHYSICS OF HOHLRAUM DISASSEMBLY}

- The hohlraum functions as an enclosure for $x$-ray radiation, providing uniform illumination of the spherical fuel capsule. Laser beams initiate the process with efficient conversion to $\mathrm{x}$-ray energy through interaction with the interior wall material of the hohlraum. Except for losses out the laser entrance holes, this emitted energy is essentially trapped within the hohlraum. The $x$ rays are continually absorbed and reemitted by the wall material, which drives the whole interior of the hohlraum to a uniformly high temperature $(\sim 300 \mathrm{eV})$. As the wall material is heated strongly by the $x$ rays, a radiation wave starts to propagate through the thickness of the wall. The balance among the energy input from the lasers, radiation losses out the LEH, and diffusion through the wall, determines the interior temperature of the hohlraum. Because radiative losses decrease and $\mathrm{x}$-ray conversion increases with higher atomic number, materials like gold are used for the hohlraum.

The dominant energy source in the hohlraum disassembly comes from the interaction of the post-burn capsule material with the hohlraum wall. LASNEX calculations show that about $75 \%$ of the yield energy escapes as neutrons. Since DT fusion gives $80 \%$ of its energy in neutrons, a significant fraction is being absorbed in the capsule material (with a very high $\rho R$ at burn time). For the 30-MJ yield cases, up to $7 \mathrm{MJ}$ is deposited in the target, compared to the input $1.8 \mathrm{MJ}$ of laser energy. Deposition of the alpha particles from the burn heats the capsule material strongly and drives a rapid expansion. This high energy capsule material stagnates against the inner wall of the gold hohlraum, creating high temperatures and pressures. Strong shocks and radiation waves are launched into the remaining hohlraum wall material. When these waves break out or burn through, the wall material radiates much of the energy as $x$ rays. The remaining energy goes to the kinetic energy of the hohlraum and capsule expansion.

The baseline target hohlraum described in the previous section is filled with a hydrogen/helium gas mixture. Calculations have shown this gas to be necessary for suppressing the "blow-in" of the wall material until late times. By keeping the material near its original location, the laser beams, which intercept the wall at angles from $23^{\circ}$ to $50^{\circ}$, deposit their energy in roughly the same axial and radial locations through the pulse. This helps to maintain $\mathrm{x}$-ray illumination symmetry within the hohlraum. It is the radial motion of gold wall material from the end caps across the LEH openings that causes the hole closure modeled in the simulations (plotted in Figure 2). 
$\mathrm{X}$-ray emission from the NIF targets can be divided into two components. One source is the radiation escaping directly out of the laser entrance holes from the hot interior of the hohlraum. The bulk of this energy is emitted when the interior is hottest (just after burn), and so it is characterized as having a high effective blackbody temperature and relatively short pulse length, as the material quickly cools from its peak temperature. Because the emission is from a hole in a blackbody enclosure, the radiation has a Lambertian distribution. (This is a cosine law dependence with the angle from the normal to the hole, with a peak of twice the isotropic fluence.) Some reduction is seen within a few degrees of the axis due to the reduced view to the hot hohlraum walls. This angular distribution has been confirmed with 2-D LASNEX runs. ${ }^{2}$ The other $x$-ray component emitted comes from transmission through and emission from the hohlraum wall. The effective emission temperature from the wall is significantly lower than from the LEH because the energy is distributed over a larger mass. The pulse length is much longer than for the LEH component because the large mass at lower temperature has a lower cooling rate than a small mass at high temperature. Since the

- emission rate goes as the fourth power of the temperature, more time is required to emit a given amount of energy. Because of the initial geometry, with gold surfaces normal to both the axial and radial directions, it is assumed that the $\mathrm{x}$-ray emission is isotropically distributed.

\section{RESULTS}

The $x$-ray output for a range of yields is given in Table 1, for a $30-\mu \mathrm{m}$ hohlraum wall. The LASNEX model captured the $\mathrm{x}$-ray emission in two components. First is the radiation leak source that simulates LEH losses. The other part is a radiation flux contour on the outside surface of the gold for transmission through and emission by the gold hohlraum wall. Shapes of spectral curves for each radiation were fit to blackbody (color) temperature (BBT) curves. A single blackbody curve fit the LEH emission spectrum for any particular run. Two blackbody temperatures were required to match the wall radiation spectra because of cooling during the long output pulse. The table lists the total energy in each component of the total $\mathrm{x}$-ray energy. The listed pulse lengths were determined from the time history plots of each component as the time for emission of from $10 \%$ to $90 \%$ of the total energy.

Table 1: Summary of NIF x-ray emissions from gold disks and $30-\mu \mathrm{m}$ wall indirect drive targets

\begin{tabular}{|c|c|c|c|c|c|c|c|c|c|c|}
\hline Target & $\begin{array}{c}\text { Yield } \\
\text { MJ }\end{array}$ & $\begin{array}{c}\text { Laser } \\
\text { Energy } \\
\text { MJ } \\
\end{array}$ & $\begin{array}{c}\text { Debris } \\
\text { Energy } \\
\text { MJ }\end{array}$ & $\begin{array}{c}\text { X-ray } \\
\text { Energy } \\
\text { MJ } \\
\end{array}$ & $\begin{array}{l}\mathrm{BBT} \\
\mathrm{eV}\end{array}$ & $\begin{array}{c}\text { Pulse } \\
10-90 \% \\
\text { ns } \\
\end{array}$ & $\begin{array}{c}5 \text { meters } \\
10^{\circ}\end{array}$ & $\begin{array}{c}\text { Fluence } \\
5 \text { meters } \\
30^{\circ} \\
\end{array}$ & $\begin{array}{c}\left(\mathrm{J} / \mathrm{cm}^{2}\right) \\
5 \text { meters } \\
50^{\circ}\end{array}$ & $\begin{array}{c}5 \text { meters } \\
90^{\circ}\end{array}$ \\
\hline disk & - & 1.0 & 0.15 & 0.70 & 200 & 3 & 0.45 & 0.39 & 0.29 & 0.00 \\
\hline disk & - & 1.8 & 0.27 & 1.26 & 200 & 3 & 0.80 & 0.69 & 0.52 & 0.00 \\
\hline $\begin{array}{l}\text { hohlraum } \\
\text { closing } \\
\text { LEH }\end{array}$ & 0.10 & 1.8 & 0.75 & $\begin{array}{c}1.08 \\
0.70 \\
0.23 \\
0.15\end{array}$ & $\begin{array}{c}255 \\
52 \\
12\end{array}$ & $\begin{array}{l}10.0 \\
61 \\
61\end{array}$ & $\begin{array}{l}\mathbf{0 . 5 7} \\
0.45 \\
0.07 \\
0.05\end{array}$ & $\begin{array}{l}\mathbf{0 . 5 1} \\
0.39 \\
0.07 \\
0.05\end{array}$ & $\begin{array}{c}0.41 \\
0.29 \\
0.07 \\
0.05\end{array}$ & $\begin{array}{c}0.12 \\
0.00 \\
0.07 \\
0.05\end{array}$ \\
\hline $\begin{array}{l}\text { hohlraum } \\
\text { closing } \\
\text { LEH }\end{array}$ & 5.00 & 1.8 & 1.15 & $\begin{array}{c}\mathbf{1 . 8 7} \\
0.94 \\
0.78 \\
0.15\end{array}$ & $\begin{array}{l}290 \\
75 \\
18\end{array}$ & $\begin{array}{l}9.0 \\
60 \\
60\end{array}$ & $\begin{array}{c}0.90 \\
0.60 \\
0.25 \\
0.05\end{array}$ & $\begin{array}{l}\mathbf{0 . 8 2} \\
0.52 \\
0.25 \\
0.05\end{array}$ & $\begin{array}{c}0.68 \\
0.39 \\
0.25 \\
0.05\end{array}$ & $\begin{array}{c}0.30 \\
0.00 \\
0.25 \\
0.05\end{array}$ \\
\hline $\begin{array}{l}\text { hohlraum } \\
\text { open } \\
\text { LEH }\end{array}$ & 5.00 & 1.8 & 0.87 & $\begin{array}{l}2.15 \\
1.70 \\
0.29 \\
0.16\end{array}$ & $\begin{array}{c}240 \\
58 \\
13\end{array}$ & $\begin{array}{l}19 \\
175 \\
175\end{array}$ & $\begin{array}{c}1.23 \\
1.08 \\
0.09 \\
0.05\end{array}$ & $\begin{array}{l}1.08 \\
0.94 \\
0.09 \\
0.05\end{array}$ & $\begin{array}{c}\mathbf{0 . 8 4} \\
0.70 \\
0.09 \\
0.05\end{array}$ & $\begin{array}{c}\mathbf{0 . 1 4} \\
0.00 \\
0.09 \\
0.05\end{array}$ \\
\hline $\begin{array}{l}\text { hohlraum } \\
\text { closing } \\
\text { LEH }\end{array}$ & 20.00 & 1.8 & 2.05 & $\begin{array}{c}4.54 \\
1.84 \\
2.50 \\
0.20\end{array}$ & $\begin{array}{c}400 \\
89 \\
18\end{array}$ & $\begin{array}{l}6.3 \\
49 \\
49\end{array}$ & $\begin{array}{c}2.03 \\
1.17 \\
0.79 \\
0.06\end{array}$ & $\begin{array}{c}1.87 \\
1.01 \\
0.79 \\
0.06\end{array}$ & $\begin{array}{c}1.61 \\
0.75 \\
0.79 \\
0.06\end{array}$ & $\begin{array}{c}0.86 \\
0.00 \\
0.79 \\
0.06\end{array}$ \\
\hline $\begin{array}{l}\text { hohlraum } \\
\text { open } \\
\text { LEH }\end{array}$ & 20.00 & 1.8 & 1.65 & $\begin{array}{l}4.94 \\
3.35 \\
1.38 \\
0.21\end{array}$ & $\begin{array}{c}320 \\
81 \\
15\end{array}$ & $\begin{array}{l}13 \\
67 \\
67\end{array}$ & $\begin{array}{c}2.64 \\
2.13 \\
0.44 \\
0.07\end{array}$ & $\begin{array}{l}2.35 \\
1.85 \\
0.44 \\
0.07\end{array}$ & $\begin{array}{c}1.88 \\
1.37 \\
0.44 \\
0.07\end{array}$ & $\begin{array}{c}0.51 \\
0.00 \\
0.44 \\
0.07\end{array}$ \\
\hline
\end{tabular}


Table 2: Double exponential curve-fit parameters (see equations $2 \& 3$ ) for $x$-ray pulses from 30- $\mu \mathrm{m}$ wall NIF hohlraums. All times are referenced to start of 20 ns laser pulse.

\begin{tabular}{|c|c|c|c|c|c|c|c|c|c|}
\hline $\begin{array}{l}\text { Yield } \\
\text { MJ }\end{array}$ & $\begin{array}{c}\mathrm{LEH} \\
\text { model }\end{array}$ & $\begin{array}{l}\text { a-LEH } \\
\mathrm{MJ} / \mathrm{ns}\end{array}$ & $\begin{array}{c}\text { b-LEH } \\
\mathrm{ns}^{-1}\end{array}$ & $\begin{array}{c}\text { c-LEH } \\
\mathrm{ns}^{-1}\end{array}$ & $\begin{array}{c}\text { to-LEH } \\
\text { ns }\end{array}$ & $\begin{array}{l}\mathrm{a}-\mathrm{Wall} \\
\mathrm{MJ} / \mathrm{ns}\end{array}$ & $\begin{array}{c}\text { b-Wall } \\
\mathrm{ns}^{-1}\end{array}$ & $\begin{array}{c}\mathrm{c} \text {-Wall } \\
\mathrm{ns}^{-1}\end{array}$ & $\begin{array}{c}\text { to-Wall } \\
\text { ns }\end{array}$ \\
\hline 0.1 & closing & 0.611 & 0.301 & 0.466 & 15.94 & 0.0109 & 0.0230 & 0.153 & 68.71 \\
\hline 5 & closing & 0.739 & 0.287 & 0.450 & 16.27 & 0.0429 & 0.0347 & 0.147 & 43.91 \\
\hline 5 & open & 0.236 & 0.133 & 3.578 & 16.76 & 0.0078 & 0.0173 & 1.568 & 53.30 \\
\hline 20 & closing & 0.741 & 0.368 & 4.332 & 20.51 & 0.1477 & 0.0503 & 0.641 & 22.33 \\
\hline 20 & open & 1.354 & 0.289 & 1.021 & 19.07 & 0.0867 & 0.0446 & 0.241 & 20.50 \\
\hline
\end{tabular}

Table 1 also gives $\mathrm{x}$-ray fluences at the first wall at various angles from the hohlraum axis. For these calculations, the assumed angular distributions were isotropic emission for wall radiation and Lambertian distribution (cosine law) for $x$ rays emitted from the LEH. Also shown in the table are the predicted outputs from shots on gold disks ( $1 \mathrm{~cm}$ diameter $\times 30 \mu \mathrm{m}$ thick), to give a more complete set of possible $\mathrm{x}$-ray source terms.

A curve-fitting technique was used to approximate the $x$-ray flux pulses obtained from the 1-D LASNEX simulations. The form of the curve fit is a double exponential. The four-parameter curve-fit equation is:

$$
\begin{aligned}
& \text { Power }=a *\left[e^{-b^{*}\left(t-t_{o}\right)}-e^{-c^{*}\left(t-t_{0}\right)}\right] \text { for }>t_{0} \\
& \text { Energy }=\left(\frac{a}{b}\right) *\left[1-e^{-b^{*}\left(t-t_{o}\right)}\right]-\left(\frac{a}{c}\right) *\left[1-e^{-c^{*}\left(t-t_{0}\right)}\right]
\end{aligned}
$$

The parameters have the following interpretations:

$$
\begin{aligned}
& \text { a - scaling to obtain the correct energy } \\
& \mathrm{b} \text { - time constant of decaying output pulse } \\
& \mathrm{c} \text { - time constant for pulse rise time } \\
& \text { to - fit to starting time of pulse relative to some } \\
& \text { reference }
\end{aligned}
$$

The double exponential fit is well suited to describing the $x$-ray pulse shapes. The (usually) rapid "turn on" of the LEH and wall emissions can be captured, as can the slow decay. The decay in the LEH $x$ rays comes from the gradual hole closure and the cooling of the hohlraum interior. The wall emission decays with its temperature as energy is lost radiatively and as the material expands into the vacuum. Table 2 contains the fit parameters for the $30-\mu \mathrm{m}$ wall hohlraums at various yields. As an example, the $\mathrm{x}$-ray pulses for a $20-\mathrm{MJ}$ shot with a $30-\mu \mathrm{m}$ hohlraum wall are shown in Figure 3.

LASNEX is typically used to predict conditions inside the hohlraum in the time before and during the thermonuclear burn. The code's ability to predict the

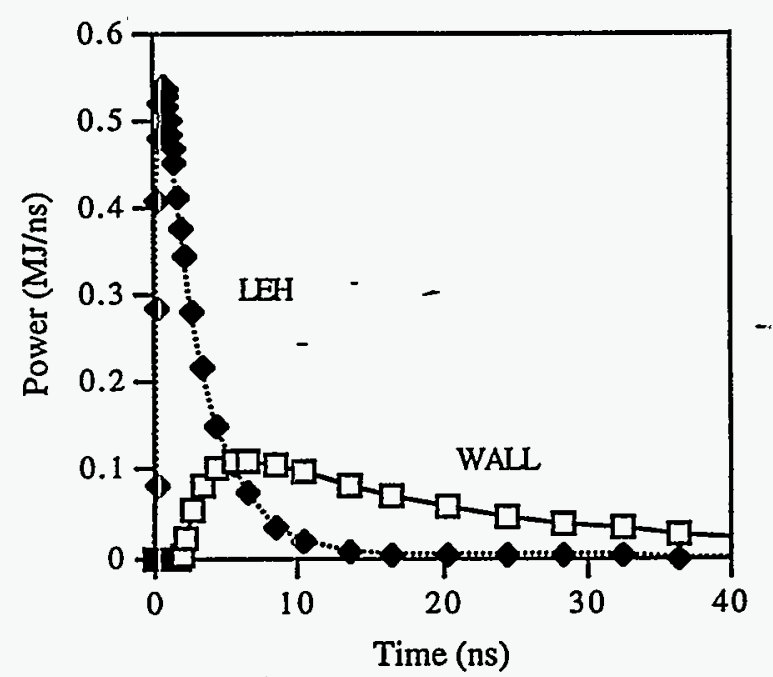

Figure 3: 20-MJ x-ray output pulse (closing LEH assumption).

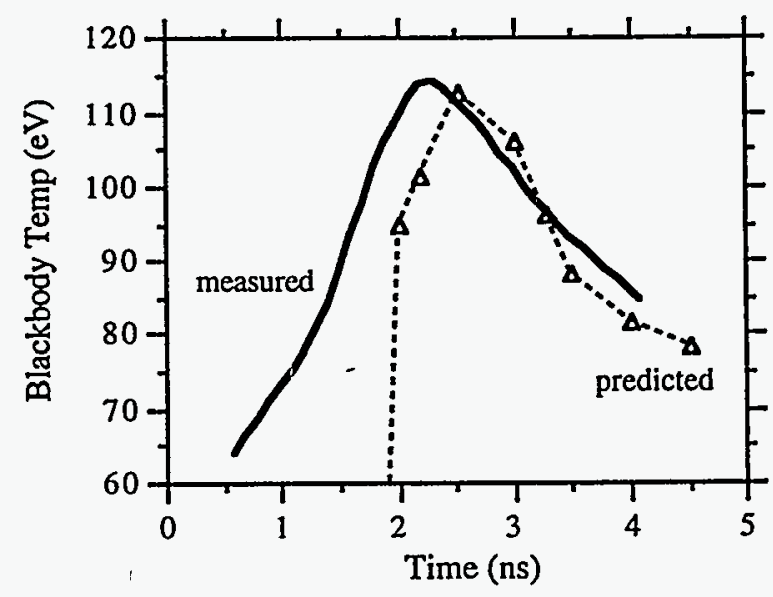

Figure 4: Effective x-ray blackbody temperature from wall of Nova hohlraum (3- $\mu \mathrm{m}$ thickness). LASNEX prediction closely matches Dante measurement. 
emission from the outside of a hohlraum wall was confirmed with two experiments on the Nova laser facility ${ }^{4}$. The $x$-ray emission of a thin-walled $(3 \mu \mathrm{m})$ gold hohlraum was measured with the Dante diagnostic 5 and compared to a LASNEX simulation. The timing of the peak emission, the rate of decay of these emissions, and effective blackbody spectra all agreed very well. Figure 4 shows close agreement between the measured spectrum and the LASNEX prediction as a function of time.

\section{DISCUSSION}

\section{A. Variations with Yield}

Figure 5 shows the fractions of non-neutron energy emitted as $x$ rays using the two bounding assumptions of LEH closure. The energy emitted from the hohlraum wall and the total $\mathrm{x}$-ray energy increase with yield. Higher energy shots drive up the temperatures of both the hohlraum interior and the bulk hohlraum wall material.
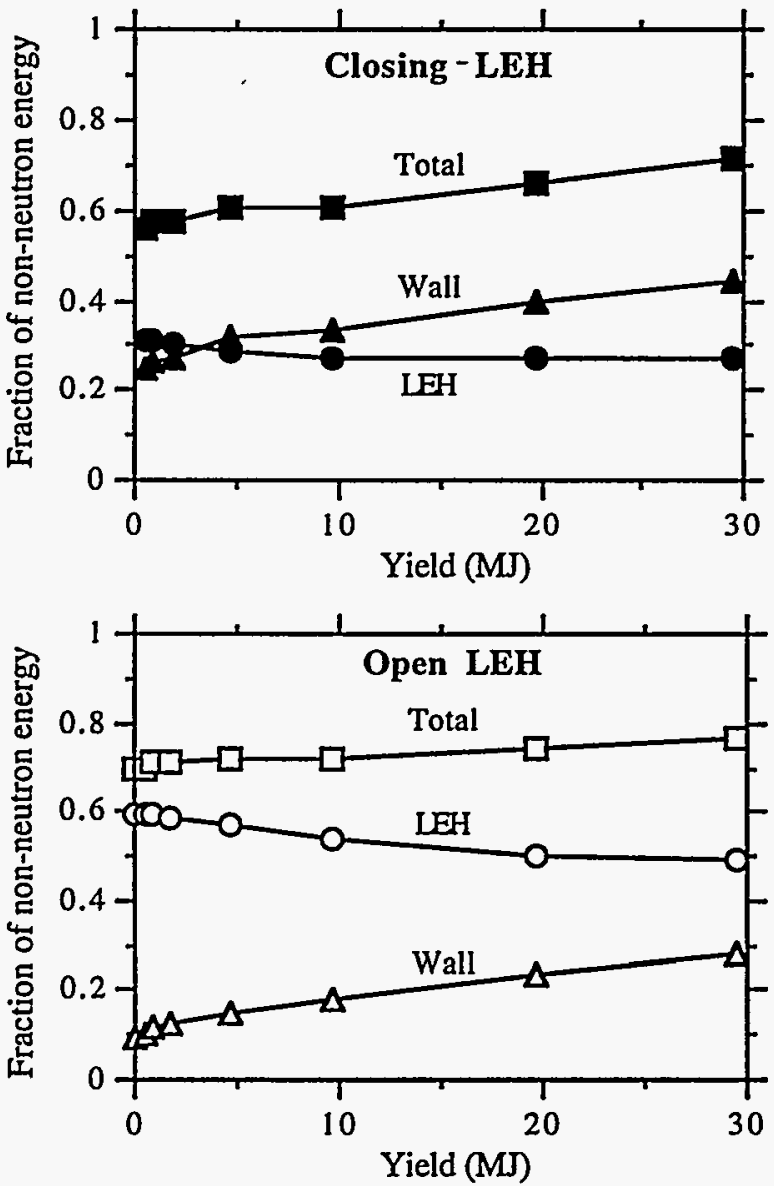

Figure 5: $X$-ray energy emission from LEH and hohlraum wall as a function of yield for closing and open LEH models. Non-neutron energy is relatively constant at $25 \%$ of total.
Radiated power is proportional to the fourth power of temperature, so the higher energy targets emit more effectively, giving a larger fraction of non-neutron energy is emitted as $\mathrm{x}$ rays.

The bounding cases of LEH treatment show a relatively small difference in the total $x$-ray emission at a given yield. What does change significantly are the relative amounts of energy from the wall and LEH. The "open" model gives a wall emission about half that of the "closing" model. This is because the internal hohlraum energy escapes quickly and is not able to couple into the wall material in the open case.

Examination of Table 1 shows that the effective blackbody temperature of the LEH emission is nearly a linear function of yield. This is expected since the kinetic energy and temperature of a gas (plasma) are related by $E=$ $3 / 2 k T$. The hohlraum is a good radiation case to maintain this temperature for the duration of the $x$-ray output pulse. The values in Table 1 show that higher yields also cause higher emission temperatures in the wall component. Because of the varying energy fractions in the two-BBT fit to the wall output, there is a more complex relation between temperature and yield.

\section{B. Variations with Wall Thickness}

It is important to determine the contribution of the LEH and wall components in specifying the $x$-ray source term, because of the differences in effective temperature, pulse length, and spatial distribution. Figure 6 presents a plot of the emitted energy in each component as a function of wall thickness. Because the thinner walls do not retain the yield energy as well as the thick walls do, the LEH energy falls off below about $30 \mu \mathrm{m}$. The wall emission, in contrast, increases quickly with lesser wall thicknesses. The radiation wave burns through the thin walls soon after bang time, so the material is quite hot and radiates effectively. The thicker walls require more time to burn through and have much more mass to heat up. This reduces the radiated energy at the expense of increased kinetic energy in the debris.

These variations give the opportunity to tailor the $\mathrm{x}$ ray emission to minimize damage to the target chamber, provided a minimum thickness is maintained to prevent burn-through (about $10 \mu \mathrm{m}$ ). A thin wall would make the $\mathrm{x}$-ray energy distribution more isotropic and would decrease the mass of target debris. But more energy would come in the colder, generally more damaging, spectrum of the wall emission. An increase in wall thickness would greatly reduce the isotropic wall component. This might be a benefit for the target positioner, for example, which has very little direct view of the LEH. Trade-offs will have to be evaluated based on an integrated analysis of the target chamber response to a particular target design. 


\section{Comparisons with Earlier Studies}

Until this detailed study was undertaken to examine the specific target designs envisioned for the NIF, the predictions for x-ray output from ICF targets were based on general trends developed for a variety of target types. In particular, it has been assumed that the non-neutron energy (the laser energy plus $20 \%$ of the yield) was evenly divided between $x$ rays and target debris. The results obtained with this series of LASNEX simulations indicate an x-ray fraction of $60-75 \%$ of the non-neutron energy, rather than $50 \%$. This represents a considerable improvement in the prediction for the NIF target chamber. In a similar way, Inertial Fusion Energy (IFE) studies could benefit from the more detailed predictive capability now available. For example, the HYLIFE II reactor design is based on the assumption of a 50/50 split of the non-neutron energy (one-third of the total target energy) between $x$ rays and debris. ${ }^{6}$
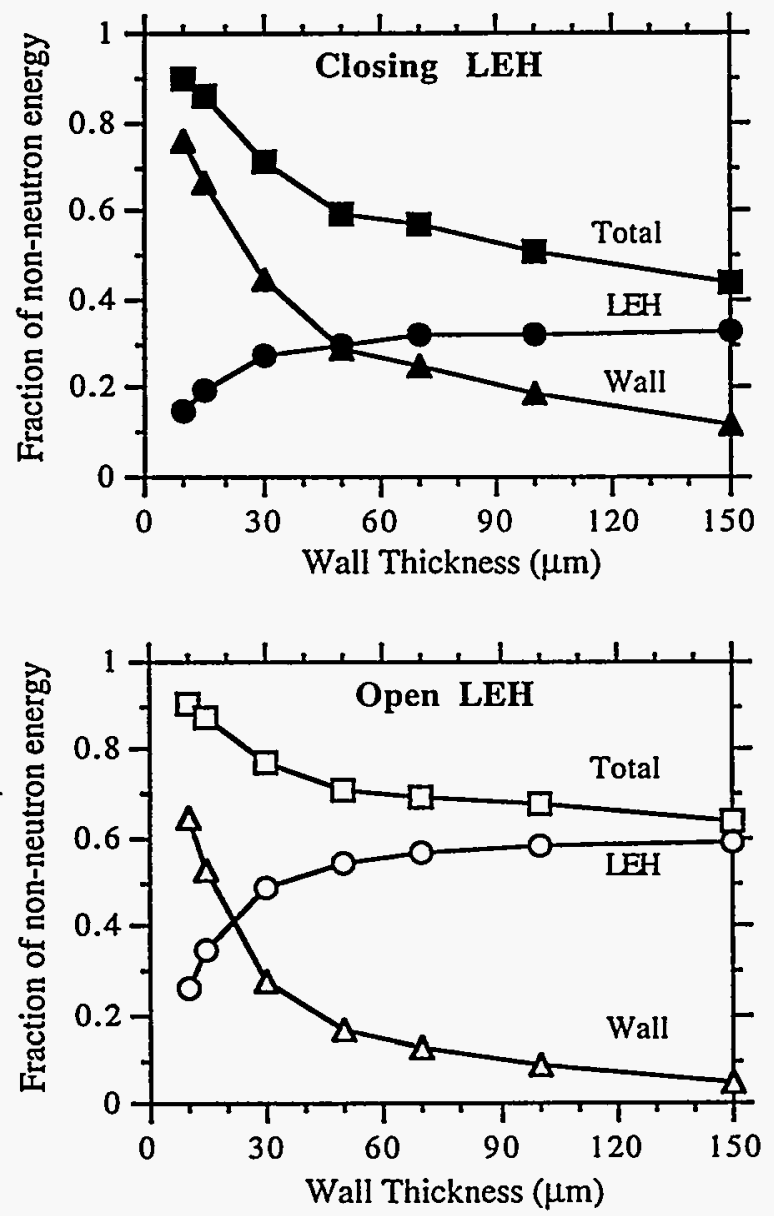

Figure 6: X-ray energy in wall and LEH emissions for 30-MJ yield targets with 8.8 MJ in non-neutron energy ( $x$ rays and debris). Top plot is for closing LEH model and bottom plot is for open LEH assumption.

\section{CONCLUSIONS}

This major effort in the simulation of the NIF x-ray threat provides a good basis for evaluating the response of target chamber structures. The validation by Nova experiment gives confidence in the accuracy of the methods. The bounding cases for the treatment of LEH closure will suffice until further 2-D simulations or Nova experiments can be performed.

\section{ACKNOWLEDGMENTS}

We would like to thank Steve Haan of LLNL for setting up the initial input deck and providing valuable guidance throughout this effort. This work was performed under the auspices of the U.S. Department of Energy by Lawrence Livermore National Laboratory under contract no. W-7405-Eng-48.

\section{REFERENCES}

1) LASNEX and Atomic Theory, LLNL Laser Program Annual Report, 1980, Vol 2, UCRL-50021-80.

2) R.R.Peterson, P.Wang, J.J.MacFarlane, G.A. Moses, "Off Axis X-Ray Emission from the Hohlraum Case of Ignited NIF Indirect Drive Targets", presented at 37th Meeting of Division of Plasma Physics, Louisville KY, Nov 6-10, 1995.

3) Haan SW, et al., "Design and Modeling of Ignition Targets for the National Ignition Facility", Physics Of Plasmas, V2 N6:2480-2487 (1995).

4) Anderson, A., Turner, R., "Benchmark Experiment for Nova Hohlraum X-Ray Emission", LLNL internal memo, L-21623-01, March 7, 1996.

5) Kornblum, H.N., Kauffman, R.L., and Smith, J.A., "Measurement of 0.1-3 keV X Rays From Laser Plasmas," Review of Scientific Instruments, V57, N8:2179-2181 (1986).

6) Moir RW, et al., "HYLIFE-II - A Molten-Salt Inertial Fusion Energy Power Plant Design - Final Report", Fusion Technology, V25 N1:5-25 (1994). 